\title{
Tubulin Beta3 Serves as a Target of HDAC3 and Mediates Resistance to Microtubule-Targeting Drugs
}

\author{
Youngmi Kim ${ }^{1,2}$, Hyuna Kim ${ }^{1,2}$, and Dooil Jeoung ${ }^{1, *}$
}

\begin{abstract}
We investigated the role of HDAC3 in anti-cancer drugresistance. The expression of HDAC3 was decreased in cancer cell lines resistant to anti-cancer drugs such as celastrol and taxol. HDAC3 conferred sensitivity to these anti-cancer drugs. HDAC3 activity was necessary for conferring sensitivity to these anti-cancer drugs. The downregulation of HDAC3 increased the expression of MDR1 and conferred resistance to anti-cancer drugs. The expression of tubulin $\beta 3$ was increased in drug-resistant cancer cell lines. ChIP assays showed the binding of HDAC3 to the promoter sequences of tubulin $\beta 3$ and HDAC6. HDAC6 showed an interaction with tubulin $\beta 3$. HDAC3 had a negative regulatory role in the expression of tubulin $\beta 3$ and HDAC6. The down-regulation of HDAC6 decreased the expression of MDR1 and tubulin $\beta 3$, but did not affect HDAC3 expression. The down-regulation of HDAC6 conferred sensitivity to taxol. The down-regulation of tubulin $\beta 3$ did not affect the expression of HDAC6 or MDR1. The down-regulation of tubulin $\beta 3$ conferred sensitivity to anti-cancer drugs. Our results showed that tubulin $\beta 3$ serves as a downstream target of HDAC 3 and mediates resistance to microtubule-targeting drugs. Thus, the HDAC3-HDAC6-Tubulin $\beta$ axis can be employed for the development of anti-cancer drugs.
\end{abstract}

\section{INTRODUCTION}

Among the numerous HDACs, histone deactylase-3 (HDAC3) is ubiquitously expressed and conserved in a wide range of species (Mahlknecht et al., 1999). HDAC3 forms large corepressor complexes containing N-CoR/SMRT and additional proteins ( $\mathrm{Li}$ et al., 2000). HDAC3 regulates the JNK pathway (Zhang et al., 2002), NF-kB activity (Chen et al., 2001), and MAPK activation (Mahlknecht et al., 2004). HDAC3 represses CREB3-mediated transcription and migration of metastatic breast cancer cells

\footnotetext{
${ }^{1}$ Department of Biochemistry, College of Natural Sciences, Kangwon National University, Chunchon 200-701, Korea, ${ }^{2}$ These authors contributed equally to this work.

*Correspondence: jeoungd@kangwon.ac.kr

Received 31 March, 2015; revised 22 May, 2015; accepted 3 June, 2015; published online 1 July, 2015
}

Keywords: anti-cancer drug-resistance, expression regulation, HDAC3, tubulin beta 3
(Kim et al., 2010a). It localizes to the mitotic spindle and is required for kinetochore-microtubule attachment (Ishii et al., 2008). Aurora kinase B plays a critical role in mitosis. Aurora kinase $B$ activity is required for mitotic processes, including kinetochore-microtubule attachment and chromosome congression (Fadri-Moskwik et al., 2012). Aurora kinase B activity is regulated by histone acetylation/deacetylation (Fadri-Moskwik et al., 2012). HDAC3 transiently interacts with Aurora kinase B and leads to reduction of acetylation of Aurora kinase (FadriMoskwik et al., 2012). Aurora kinase B is active in its deacetylated state (Fadri-Moskwik et al., 2012). Over-expression of Aurora kinase has been reported in multiple tumors and the selective inhibition of Aurora kinase $B$ results in apoptosis induction (Xie et al., 2013). Aurora kinase B is regulated by the MAPK/ERK pathways and is a potential target for overcoming resistance to vemurafenib in metastatic melanomas (Bonet et al., 2012)

Phase I trial revealed that albumin-bound paclitaxel shows encouraging activity against advanced metastatic melanomas (Ott et al., 2013). Resistance to taxol, a microtubule-targeting drug, in hepatoma cells is related to JNK activation and prohibition into mitosis (Chae et al., 2012). Taxol-resistance results from MAPK activation (Xu et al., 2011). The inhibition of MAPK enhances taxol-induced apoptosis (Xu et al., 2009). As HDAC3 suppresses JNK (Zhang et al., 2002) and MAPK activation (Mahlknecht et al., 2004), it is likely that HDAC3 may regulate taxol-resistance.

The increased expression level of tubulin $\beta 3$ is closely related with resistance to taxol (Kavallaris et al., 1997). High tubulin $\beta 3$ expression is closely related with non-responsiveness to chemotherapy and is regulated by multiple signaling pathways, including PI3 kinase/Akt, Ras and MAP-ERK kinase (Levallet et al., 2012). HDAC6 deacetylates alpha-tubulin and regulates microtubule-dependent cell motility (Hubbert et al., 2002). This suggests that histone acetylation/deacetylation may also regulate activity and/or expression of tubulins. These reports suggested potential role of HDAC3 in resistance to microtubuletargeting drugs, including taxol. However, the role of HDAC3 in resistance to microtubule-targeting drugs in cancer cell lines in relation with tubulin $\beta 3$ remains unknown. In this study, we investigated the molecular relationship between HDAC3 and tubulin $\beta 3$. We showed that the low expression level of HDAC3 is related with the resistance to microtubule-targeting drugs. We showed that HDAC3 confers sensitivity to microtubule-targeting drugs. HDAC3 directly regulates the expression of MDR1 by binding to its promoter sequence. The expression of tubulin $\beta 3$ was increased in cancer cell lines resistant to microtubule- 
targeting drugs and HDAC3 decreased the expression of tubulin $\beta 3$. HDAC3 showed direct binding to the promoter sequences of tubulin $\beta 3$. HDAC6 showed an interaction with tubulin $\beta 3$ that was disrupted by HDAC3. HADC6 acted upstream of tubulin $\beta 3$, and the down-regulation of HDAC6 enhanced sensitivity to microtubule-targeting drugs. Tubulin $\beta 3$ did not affect expression MDR1. The down-regulation of MDR1 did not affect the expression of tubulin $\beta 3$, either. Our results indicated that tubulin $\beta 3$ is an independent target of HDAC3.

\section{MATERIALS AND METHODS}

\section{Materials}

Anti mouse and anti rabbit IgG-horse radish peroxidase conjugate antibodies were purchased from Pierce Company. An ECL (enhanced chemiluminiscence) kit was purchased from Amersham. Lipofectamin and Plus ${ }^{\mathrm{TM}}$ reagent were purchased from Invitrogen (USA). Bioneer (Korea) synthesized all primers and oligonucleotides oused in this study. All antibodies used in this study were purchased from Santa Cruz Company.

\section{Cell lines and cell culture}

Cancer cell lines used in this study were cultured in Dulbecco's modified minimal essential medium (DMEM; Gibco, USA) supplemented with heat-inactivated $10 \%$ fetal bovine serum (FBS, Gibco) and antibiotics at $37^{\circ} \mathrm{C}$ in a humidified incubator with a mixture of $95 \%$ air and $5 \% \mathrm{CO}_{2}$. Cancer cell lines (SNU387 and Malme $3 \mathrm{M}^{\mathrm{R}}$ ) made resistant to microtubule-targeting drugs were established by stepwise addition of the respective drug. Cells surviving drug treatment (attached fraction) were obtained and used throughout this study. SNU387/SNU387 ${ }^{\mathrm{R}}$ or Malme3M/Malme $3 \mathrm{M}^{\mathrm{R}}$ cells that stably express anti-sense HDAC3 cDNA, HDAC3-Flag or mutant HDAC3 were selected by $\mathrm{G} 418(400 \mu \mathrm{g} / \mathrm{ml})$.

\section{Western blot analysis}

Western blot analysis, immunoprecipitation and cellular fractionation were performed according to the standard procedures (Kim et al., 2010b).

\section{Cell viability determination}

The cells were assayed for their growth activity using the 3-(4, 5-dimethylthiazol-2-yl)-2, 5-diphenyltetrazolium bromide (MTT; Sigma). Viable cell number counting was carried out by trypan blue exclusion assays.

\section{HDAC3 constructs}

$\mathrm{HDAC3}^{\mathrm{S} 424 \mathrm{~A}}-\mathrm{Myc}_{\mathrm{H}} \mathrm{His}_{(6)}$ expression plasmid (catalytically inactive HDAC3 mutant) was derived from pHDAC3-Myc/His ${ }_{(6)}$ with the Quick-change site-directed mutagenesis kit (Stratagene).

\section{Transfection}

All transfections were performed according to the manufacturer's instructions. Lipofectamine and Plus reagents (Invitrogen) were used.

\section{Histone deacetylase activity assays}

Histone deacetylase activity was measured according to the manufacturer's instructions (Cayman Chemical, USA). The activity was measured according to the manufacturer's instructions. For immunoprecipitation, cells were lysed with ice-cold buffer (10 mM Tris- $\mathrm{HCl}, \mathrm{pH} 7.4,10 \mathrm{mM} \mathrm{NaCl}, 15 \mathrm{mM} \mathrm{MgCl}$, 250 mMsucrose, $0.12 \mathrm{mM}$ EDTA, $0.5 \%$ Nonidet P-40, and a mixture of protease inhibitors). The lysates were suspended with nuclear extraction buffer (50 mM HEPES, pH 7.5, $420 \mathrm{mM}$ $\mathrm{NaCl}, 0.5 \mathrm{mMn}$ EDTA, $0.1 \mathrm{mM}$ EGTA, and 10\% glycerol), sonicated for $30 \mathrm{~s}$, and centrifuged at $10,000 \mathrm{~g}$ for $10 \mathrm{~min}$ at $4^{\circ} \mathrm{C}$. The supernatant containing the nuclear extract was immunoprecipitated with anti-HDAC3 $(2 \mu \mathrm{g} / \mathrm{ml})$, anti-HDAC2 (2 $\mu \mathrm{g} / \mathrm{ml})$, or anti-lgG antibody $(2 \mu \mathrm{g} / \mathrm{ml})$. The immunoprecipitants were incubated with $200 \mu \mathrm{M}$ acetylated fluorometric substrate for $30 \mathrm{~min}$ at $37^{\circ} \mathrm{C}$, and $40 \mu$ of developer was added. After 15 min, the fluorescencewas measured using an excitation wavelength of 340-360 $\mathrm{nm}$ and an emission wavelength of 440-460 $\mathrm{nm}$.

\section{Caspase- 3 activity assays}

Caspase- 3 activity was measuredaccording to the manufacturer's instructions (BioVision, USA). Cells were lysed in $0.1 \mathrm{M}$ HEPES buffer, $\mathrm{pH} 7.4$, containing $2 \mathrm{mM}$ dithiothreitol, $0.1 \%$ CHAPS, and $1 \%$ sucrose. Cell lysates were incubated with a colorimetric substrate, $200 \mu \mathrm{M}$ Ac-DEVD-p-nitroanilide, for 30 $\mathrm{min}$ at $30^{\circ} \mathrm{C}$. The fluorescence was measured at $405 \mathrm{~nm}$ using a microtiter plate reader.

\section{ChIP assays}

Assays were performed according to manufacturer's instruction (Upstate). The immunoprecipitates were reverse cross-linked. PCR was done on the phenol-chloroform-extracted DNA. PCR was done on the phenol-chloroform-extracted DNA with specific primers of tubulin $\beta 3$ promoter-1 [5'-GCAGCAGTCGCCCAAGCAGA-3' (sense)] and [5'-CAGCCCACCTGCACTGAGCC-3' (antisense)], tubulin 33 promoter-2 [5'-GCTCAGTGCAGGTGGGCTGG-3' (sense)] and [5'-CCTGCCCCACAGTGTGCTCG-3' (antisense)], HDAC6 promoter-1[5'-TACAGAAACACCTGTGACCC-3' (sense)] and [5'-ATCTGTGCTGTAGTGTCAGG-3' (antisense)], HDAC6 promoter-2 [5'-TGCTTATCTCTCCGGTCCCA-3' (sense)] and [5'-CTGCGGTGCAAGCTTTTTCT-3' (antisense)], HDAC6 promoter-3 [5'-AGAAAAAGCTTGCACCGCAG-3' (sense)] and [5'-CCCCATTCCCAGACCCTCTA-3' (antisense)] sequences were used.

\section{Preparation of SiRNA duplexes}

The SiRNA duplexes were constructed with the following target sequences. Tubulin $\beta 3$, sense (5'-AAGCCTCTTCCTCACAAGTACGCCTGTCTC-3'); antisense (5'-AACGGAGAAGAGTGTTCATGCCCTGTCTC-3'); HDAC6, sense (5'-AAGGTGTCACCTGAGGGTTATCCTGTCTC-3'); antisense (5'-AAATAACCCTCAGGTGACACCCCTGTCTC-3'); MDR1-1, sense (5'-AATCCAAGGCATCAATTTCACCCTGTCTC-3'); antisense (5'-AAGTGAAATTGATGCCTTGGACCTGTCTC-3'); MDR1-2, sense (5'-AATTGCATACGCTAAGAGTTCCCTGTCTC-3'); antisense (5'-AAGAACTCTTAGCGTATGCAACCTGTCTC-3'); Control, sense (5'-AATTCTCCGAACGTGTCACGTCCTGTCTC$3^{\prime}$ ); antisense (5'-AAACGTGACACGTTCGGAGAACCTGTCTC-3'). The construction of SiRNA was carried out according to the instruction manual provided by the manufacturer (Ambion, USA).

\section{Statistical analysis}

Statistical differences in this were determined by using the Student's $t$ test.

\section{RESULTS}

Taxol-resistant cancer cell lines show lower expression level of HDAC3 than taxol-sensitive cancer cell lines We established cancer cell lines selected for resistance to 
A

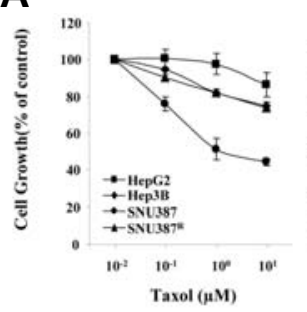

D

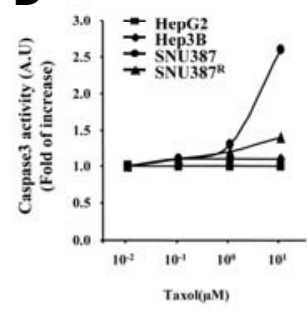

B
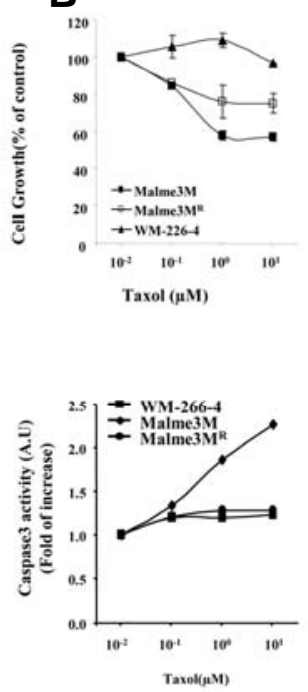

C

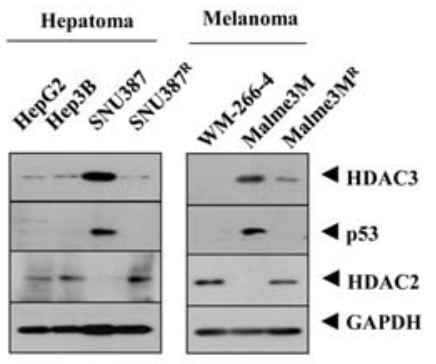

E

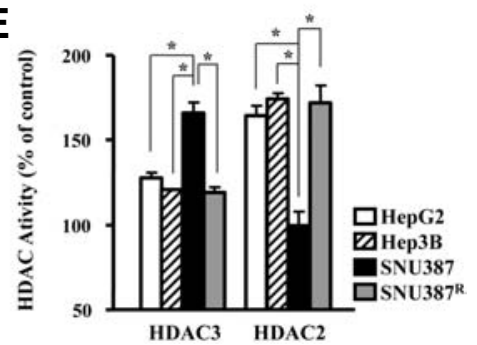

Fig. 1. Low expression of HDAC3 is correlated with resistance to taxol. (A) The indicated hepatoma cell line was treated with various concentrations of taxol for $48 \mathrm{~h}$, followed by MTT assays. Hep3B, SNU387 and SNU387 ${ }^{\mathrm{R}}$ are the hepatocellular carcinoma cell lines, and HepG2 is a hepatoma cell line. The numbers are average of three independent experiments. Each experiment consists of triplicate measurement. (B) The indicated hepatoma cell line was treated with various concentrations of taxol for $48 \mathrm{~h}$, followed by MTT assays. Each value represents an average obtained from 3 independent experiments. Data is expressed as a mean \pm SD. (C) Cell lysates from the indicated cancer cell line were subjected to Western blot analysis. The representative figures are provided from three independent experiments. (D) The indicated hepatoma cell line was treated with various concentrations of taxol for $48 \mathrm{~h}$,
HDAC activity assays as described. ${ }^{*} p<$

followed by MTT assays. (E) Cell lysates isolated from the indicated cancer cell line were subjected to HDAC activity assays as described. ${ }^{*} p<$
0.05 .

celastrol, a microtubule-targeting drug. We examined the role of HDAC(s) in resistance to microtubule-targeting drugs such as celastrol and taxol. Hepatoma cell lines i.e., HepG2, Hep3B and SUN387 ${ }^{R}$ cells showed resistance to taxol (Fig. 1A). Melanoma cell line WM266-4 and Malme3MR showed resistance to taxol (Fig. 1B). SNU387 ${ }^{\mathrm{R}}$ and Malme3MR cells are cancer cells selected for resistance to celastrol. HepG2, Hep3B and SUN387 ${ }^{R}$ showed lower expression of HDAC3 than taxolsensitive SNU387 cells (Fig. 1C). Furthermore, WM266-4 and Malme3M ${ }^{R}$ showed lower expression of HDAC3 than taxolsensitive Malme $3^{\mathrm{M}}$ cells (Fig. 1C). The expression of HDAC3 in these cancer cell lines showed correlation with the expression of p53 (Fig. 1C). HDAC3 expression was inversely related to HDAC2 expression (Fig. 1C). SNU387 and Malme3M cells showed higher caspase- 3 activity than the respective controls (Fig. 1D). This finding suggested that sensitivity of SNU387 and Malme3M cells to taxol results from caspase- 3 activation. HDAC3 expression level is correlated with HDAC3 activity, similar to HDAC2 (Fig. 1E). The expression level of HDAC3 and HDAC2 showed correlation with their activity in melanoma cells employed in this study (data not shown). These results suggested that the expression level of HDAC3 might determine the response to microtubule-targeting drugs.

HDAC3 confers sensitivity to microtubule-targeting drugs Because the down-regulation of HDAC 3was correlated with resistance to taxol, we hypothesized that over-expression of HDAC3 confers sensitivity to microtubule-targeting drugs. In this study, we employed catalytically inactive mutant $\mathrm{HDAC}^{\mathrm{S424A}}$ to determine whether HDAC3 activity is necessary to confer sensitivity to microtubule-targeting drugs. Ser424 is a non-conserved residue among class I HDACs. Ser 424 is the the protein kinase CK2 phosphoacceptor site in HDAC3 (Zhang et al., 2005). HDAC3 $^{\text {Ser424 }}$ lacks histone deacetylase activity (Zhang et al., 2005). Wild type HDAC3, but not HDAC3 ${ }^{\text {S424A }}$, enhanced the sensitivity of HepG2, Hep3B and WM-266-4 cells (Figs. 2A, 2C, and $2 \mathrm{E}$ ) to microtubule-targeting drugs such as celsatrol, taxol and vinblastine. The enhanced sensitivity was accompanied by enhanced cleavages of PARP and caspase- 3 in these cancer cells (Figs. 2B, 2D, and 2F). These results suggested that HDAC3 activity is necessary for conferring sensitivity to microtubule-targeting drugs. We established cancer cell lines that stably express anti-sense HDAC3 (SNU387-As-HDAC3, Mame3MAs-HDAC3) to further confirm the role of HDAC3. SNU387-AsHDAC3 cells and Malme3M-As-HDAC3 cells showed higher resistance to microtubule-targeting drugs than the respective controls (Table 1). They also showed increased expression of MDR1 (Figs. 3A and 3B). Wild type HDAC3, but not $\mathrm{HDAC}^{\text {Ser424A }}$, enhanced cleavages of PARP and caspase-3 in SNU387-As-HDAC3 and Malme3M-As-HDAC3 in response to microtubule-targeting drugs (Figs. $3 \mathrm{C}$ and $3 \mathrm{D}$ ). Wild type HDAC3, but not HDAC3 ${ }^{424 A}$, enhanced the sensitivity of SNU387-AsHDAC3 cells and Malme3M-As-HDAC3 cells to microtubuletargeting drugs (Table 1). This result confirmed that resistance to microtubule-targeting drugs results from the down-regulation of HDAC3. Taken together, these results suggested that HDAC3 regulates response to microtubule-targeting drugs.

HDAC3 directly regulates the expression of tubulin $\beta 3$ Over-expression of tubulin $\beta 3$ is involved in resistance to microtubule-targeting drugs (Kavallaris et al., 1997). We hypothesized that HDAC3 would be a negative regulator of tubulin $\beta 3$. SNU387 ${ }^{\mathrm{R}}$ and Malme3M ${ }^{\mathrm{R}}$ cells showed higher expression levels of tubulin $\beta 3$ than SNU387 and Malme3M cells (Fig. 4A). HDAC6 interacts with tubulin $\beta 3$ and causes deacetylation (Zhang et al., 2003). HDAC6 showed an interaction with tubulin $\beta 3$ in SNU387 ${ }^{R}$ and Malme3M ${ }^{R}$ cells (Fig. 4A). SNU387-ASHDAC3 and Malme3M-AS-HDAC3 cells stably expressing anti sense HDAC3 showed increased expression of HDAC6 and tubulin $\beta 3$ (Fig. 4B), suggesting that HDAC3 may act as a 
The Roles of HDAC3 in Microtubule-Targeting Drugs Resistance

Youngmi Kim et al.

$\boldsymbol{A}$
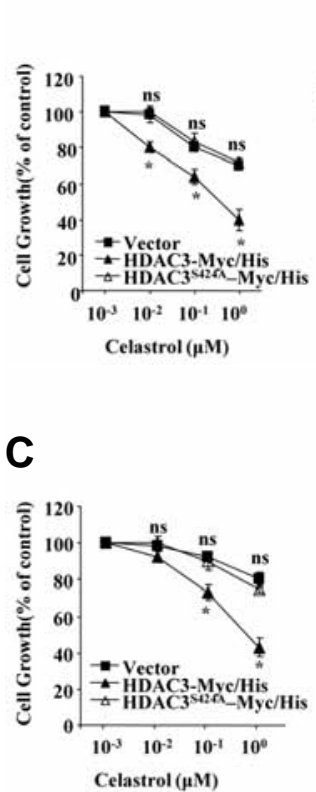

$E$

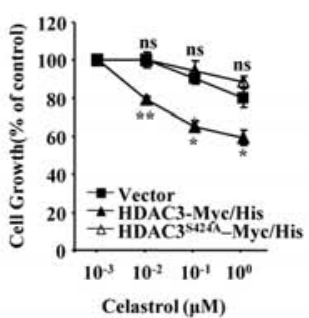

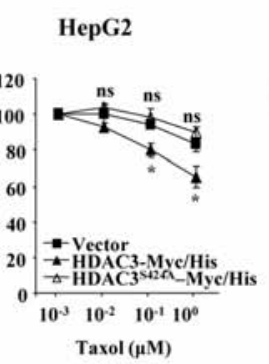
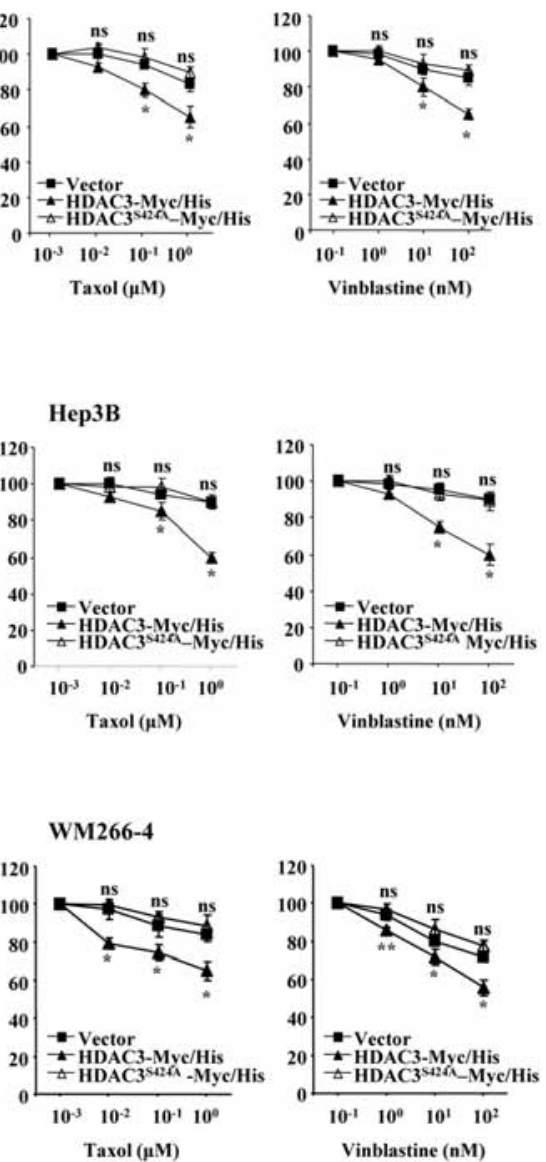

B

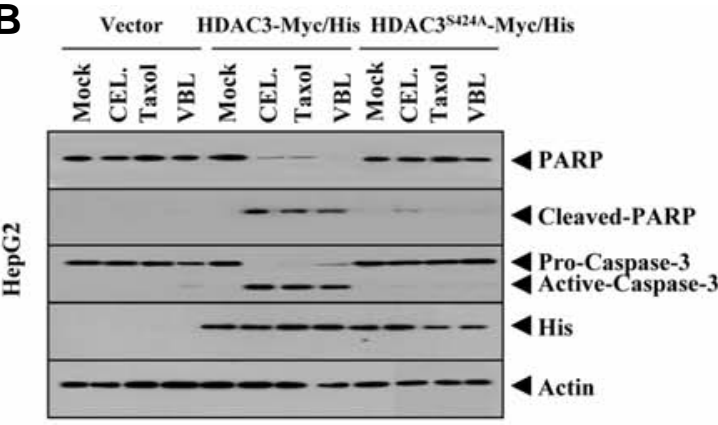

D

Vector HDAC3-Myc/His HDAC3 ${ }^{\operatorname{si2} 2 \mathrm{~A}-\mathrm{Myc} / \mathrm{His}}$

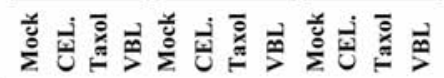

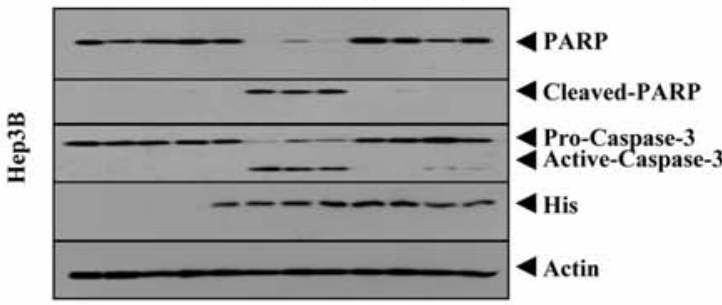

$\boldsymbol{F}$
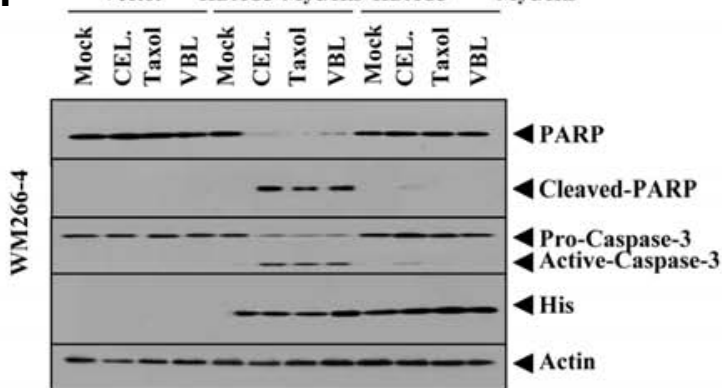

Fig. 2. HDAC3 confers sensitivity to celastrol, taxol and vinblastine in cancer cell lines that express low levels of HDAC3. Each indicated drugresistant cancer cell line was transiently transfected with control vector $(1 \mu \mathrm{g})$, HDAC3-His $(1 \mu \mathrm{g})$ or HDAC3 $(\mathrm{S} 424 \mathrm{~A})$-His $(1 \mu \mathrm{g})$. The next day, cells were treated with or without various concentrations of the indicated drugs for $24 \mathrm{~h}$. MTT assays were performed $(\mathrm{A}, \mathrm{C}$, and $\mathrm{E})$. ${ }^{*} p<0.005$ ${ }^{* *} p<0.0005$. P value was determined in comparison with value obtained from HepG2, Hep3B or WM-266-4 cells transfected with control vector. NS denotes not significant. Each indicated drug-resistant cancer cell line was transiently transfected with control vector, HDAC3-Myc/His or HDAC3 ${ }^{\mathrm{S} 24 \mathrm{~A}}-\mathrm{Myc} / \mathrm{His}$. The next day, cells were treated with the indicated drugs ( $1 \mu \mathrm{M}$ for celastrol and taxol; $100 \mathrm{nM}$ for vinblastine) for $24 \mathrm{~h}$, followed by Western blot analysis (B, D, and F). VBL denotes vinblastine and CEL denotes celastrol.

negative regulator of HDAC6 and tubulin $\beta 3$. Wild type HDAC3, but not mutant HDAC3 (S424A), decreased the expression of HDAC6 and tubulin $\beta 3$ and prevented an interaction between HDAC6 and tubulin $\beta 3$ (Fig. 4C). Celastrol and taxol led to the decreased expression of HDAC3 while increasing the expression of tubulin $\beta 3$ (Fig. 4D), suggesting that HDAC3 and tubulin $\beta 3$ are involved in anti-cancer drug-resistance. The decreased expression of HDAC3 preceded the increased expression of tubulin $\beta 3$ by these anti cancer drugs (Fig. 4D), suggesting that HDAC3 functions upstream of tubulin $\beta 3$. Tubulin $\beta 3$ promoter contains putative binding sites for various transcription regulators such as DNMT1, Snail, HDAC2, AP1 and SP1 (Fig. 4E). ChIP assays showed the binding of HDAC3 to the promoter sequences of tubulin $\beta 3$ (Fig. 4F). The down-regulation of tubulin $\beta 3$ increased sensitivity to microtubule-targeting drugs via apoptosis (Figs. 5A and $5 \mathrm{~B}$ ). The down-regulation of HDAC6 decreased the expression of tubulin $\beta 3$ and MDR1, but not
HDAC3 in SNU387 ${ }^{R}$ and Malme3M ${ }^{R}$ cells (Fig. 5C). The downregulation of tubulin $\beta 3$ did not affect the expression of HDAC6 or MDR1 (Fig. 5C). Taken together, these results suggested that tubulin $\beta 3$ serves as an independent target of HDAC3 and HDAC6.

HDAC3 shows binding to the promoter sequences of HDAC6 Because HDAC3 exerted a negative regulation on the expression of HDAC6 (Fig. 4B), we examined the possibility of direct regulation of HDAC6 by HDAC3. HDAC6 promoter contains putative binding sites for HDAC2, DNMT1, YY1, and Snail (Fig.6A). SNU387 ${ }^{R}$ and Malme3M ${ }^{R}$ cells showed higher expression levels of HDAC1, -2 and -6 than their respective controls (Fig. 6B). SNU387 ${ }^{\mathrm{R}}$ and Malme $3 \mathrm{M}^{\mathrm{R}}$ cells also showed higher expression level of $Y Y 1$ (Fig. 6B). YY1 interacts with histone acetyltransferases p300 and histone deacetylase 1 (HDAC1), HDAC2, and HDAC3 (Yao et al., 2001). The activity of YY1 is 
Table 1. Drug-sensitivity and relative resistance of SNU387-As-HDAC3 and Malme3M-A-HDAC3 cell lines transiently transfected with wild type or mutant HDAC3. To determine $\mathrm{IC}_{50}$ values, SNU387 or Malme3M cells were treated with or without various concentrations of the indicated drugs for $48 \mathrm{~h}$. To determine the effect of wild type or mutant HDAC3 on IC ${ }_{50}$ values, SNU387-As-HDAC3 or Malme3M-As-HDAC3 cells were transiently transfected with the indicated construct. At $24 \mathrm{~h}$ after transfection, cells were treated with or without the indicated drug at various concentrations for $48 \mathrm{~h}$. MTT assays were performed.

\begin{tabular}{|c|c|c|c|}
\hline & & Drug $\mathrm{IC}_{50}{ }^{\mathrm{a}}(\mathrm{RF})$ & \\
\hline & Celastrol $(\mu \mathrm{M})$ & Taxol $(\mu \mathrm{M})$ & Vinblastine (nM) \\
\hline SNU387 & $0.84 \pm 0.039$ & $0.82 \pm 0.184$ & $3.47 \pm 0.102$ \\
\hline \multicolumn{4}{|c|}{ SNU387-AS-HDAC3 } \\
\hline Vector & $2.49 \pm 0.020\left(2.9^{c}\right)$ & $2.75 \pm 0.001(3.3)$ & $10.21 \pm 0.021(2.9)$ \\
\hline HDAC3-His & $1.08 \pm 0.016(1.2)$ & $1.03 \pm 0.030(1.3)$ & $4.27 \pm 0.240(1.2)$ \\
\hline $\mathrm{HDAC3}^{\mathrm{S} 24 \mathrm{~A}}$-His & $2.11 \pm 0.031(2.5)$ & $2.38 \pm 0.029(3.0)$ & $8.89 \pm 0.207(2.6)$ \\
\hline Malme3M & $0.60 \pm 0.043^{\mathrm{b}}$ & $0.50 \pm 0.070$ & $8.00 \pm .230$ \\
\hline \multicolumn{4}{|c|}{ Malme3M-AS-HDAC3 } \\
\hline Vector & $1.89 \pm 0.159\left(3.1^{\mathrm{C}}\right)$ & $1.65 \pm 0.205(3.3)$ & $17.04 \pm 0.121$ \\
\hline HDAC3-His & $0.78 \pm 0.019(1.3)$ & $0.63 \pm 0.003(1.2)$ & $8.54 \pm 0.020(1.1)$ \\
\hline $\mathrm{HDAC}^{\mathrm{S424A}}$-His & $1.75 \pm 0.250(2.9)$ & $1.35 \pm 0.107(2.7)$ & $16.09 \pm 0.153(2.0)$ \\
\hline
\end{tabular}

${ }^{a} \mathrm{IC}_{50}$, the concentration of drug required to inhibit cell growth by $50 \%$. ${ }^{\mathrm{b}}$ Mean \pm s.d. of at least 3 independent experiments. ${ }^{\mathrm{C}} \mathrm{RF}$, resistance factor $\left(\mathrm{IC} \mathrm{C}_{50}\right.$ in SNU387-As-HDAC3 or Malme3M-As-HDAC3 transfected with control vector $/ I_{50}$ in SNU387 or Malme3M cell line).

A

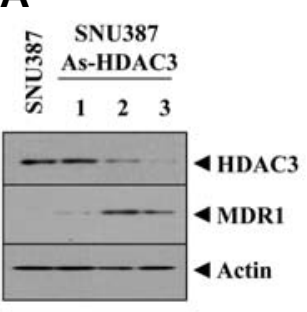

$c$

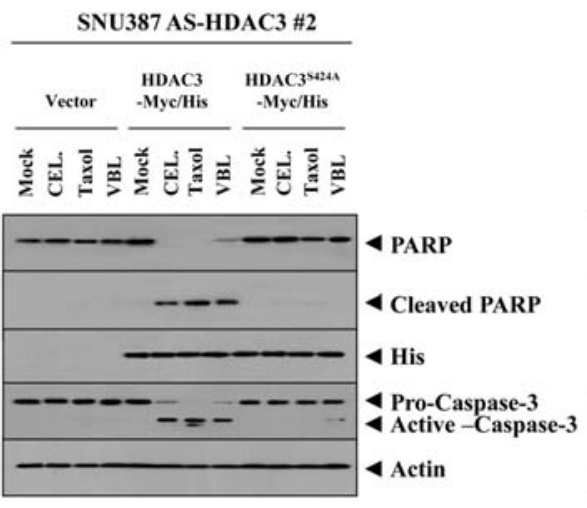

D
B
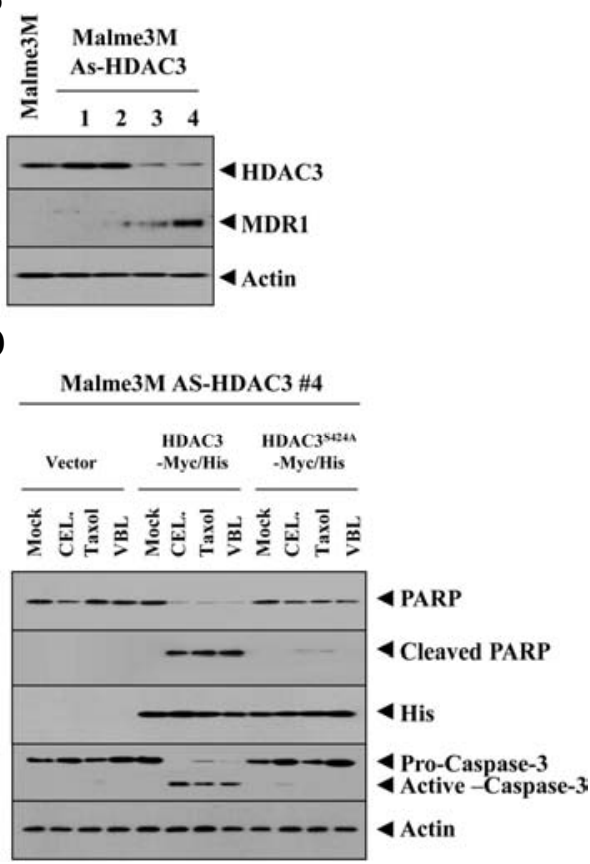

Fig. 3. Wild type, but not mutant HDAC3, confers sensitivity to microtubule-disrupting drugs in cancer cell lines that stably express antisenseHDAC3. Cell lysates from the indicated cell line were subjected to Western blot (A, B). (C) SNU387 cells that stably express antsense-HDAC3 (SNU387As-HDAC3) were transiently transfected with control vector, HDAC3$\mathrm{Myc} / \mathrm{His}$ or $\mathrm{HDAC}^{\mathrm{S} 424 \mathrm{~A}}-\mathrm{Myc} / \mathrm{His}$. At $24 \mathrm{~h}$ after transfection, cells were treated with or without celastrol (1 $\mu \mathrm{M})$, taxol $(1 \mu \mathrm{M})$ or vinblastine $(100$ $\mathrm{nM})$ for $24 \mathrm{~h}$, followed by Western blot analysis. (D) The same as C except that Malme3M-As-HDAC3 cell line was employed. regulated through acetylation by $\mathrm{p} 300$ and deacetylation by HDACs. In other words, $Y Y I$ is active in its deacetylated state. ChIP assay showed the binding of HDAC1 and -2 to the promoter sequences of HDAC6 (Fig. 6C). YY1 may recruit HDAC1 and/or HDAC2 to the promoter sequences of HDAC6. HDAC3 did not show binding to the site 1 of HDAC6 promoter (data not shown). We therefore focused on ChIP assays employing sites 2 and 3 of the HDAC6 promoter sequences. Wild type HDAC3, but not mutant HDAC3 (HDAC3 S424A), showed binding to HDAC6 promoter sequences in drug-sensitive Malme3M cells
(Fig. 6C). This suggested the direct involvement of HDAC3 in the regulation of HDAC6 expression. HDAC3 exerted negative effects on the binding of HDAC1 and -2 to the promoter sequences of HDAC6 (Fig. 6C). It is probable that HDAC1 and -2 may be involved in resistance to microtubule-targeting drugs. SNU387 ${ }^{R}$ cells showed higher expression level of Ac-H3K9/14 and Ac-H4 K16 (data not shown). HDAC3 exerted a negative effect on the binding of $\mathrm{Ac}-\mathrm{H} 3 \mathrm{~K} 9 / 14$ and $\mathrm{Ac}-\mathrm{H} 4 \mathrm{~K} 16$ to the promoter sequences of HDAC6 (Fig. 6C). In addition, YY1 showed binding to the promoter sequences of HDAC6 that was 
A

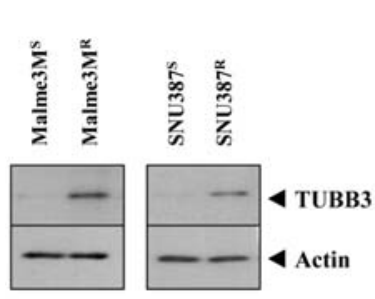

IB

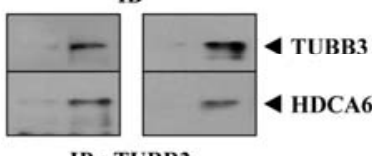

IP : TUBB3

B

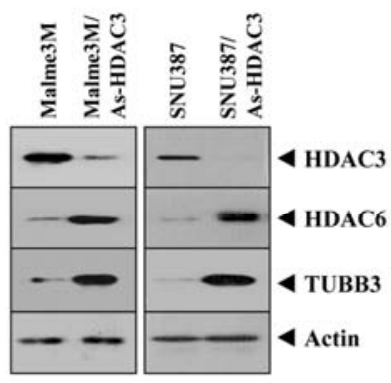

IB

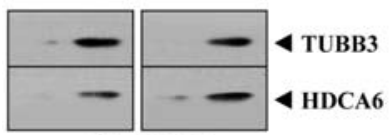

$C_{\text {Malme3 } \mathrm{M}^{\mathrm{n}}}$

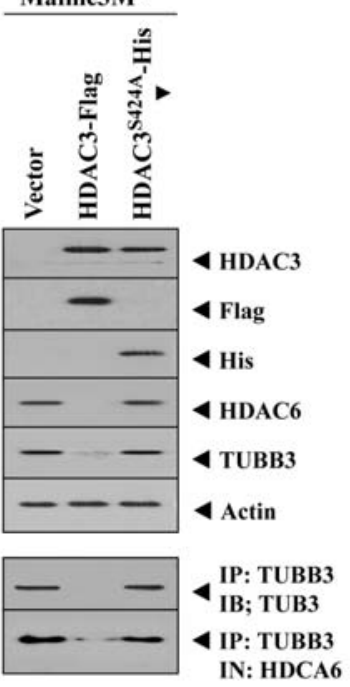

$D$

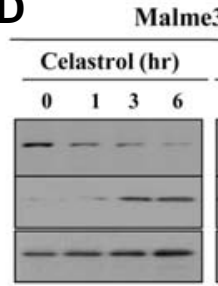

Malme3M

\begin{tabular}{cccc}
\multicolumn{3}{c}{ Taxol (hr) } \\
\hline 0 & 0.5 & 1 & 2
\end{tabular}

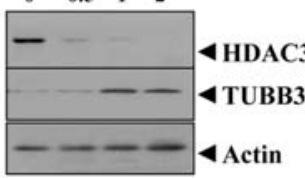

$E$

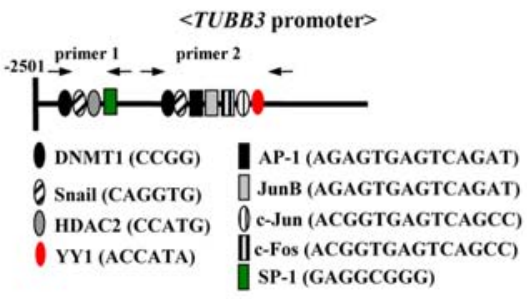

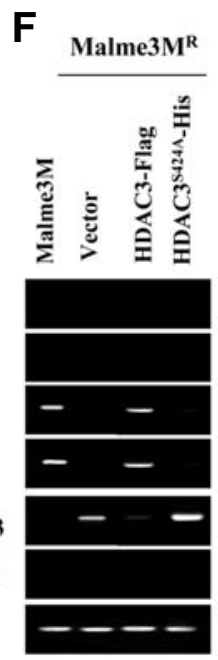

SNU387 ${ }^{\mathrm{R}}$

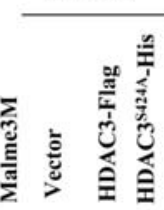

PCR:

\begin{tabular}{l|l}
$\frac{\text { TUBB3 }}{\text { Primer 1 }}$ & \multicolumn{1}{|l}{ IP : } \\
Primer 2 & IgG \\
Primer 1 & $\begin{array}{l}\text { HDAC3 } \\
\text { Flag }\end{array}$ \\
Primer 2 & $\begin{array}{l}\text { His } \\
\text { Primer 1 }\end{array}$ \\
Primer 2 & HDAC6 \\
Input
\end{tabular}

Fig. 4. HDAC3 regulates expression of tubulin $\beta 3$ and the interaction between HDAC6 and tubulin $\beta 3$. (A) Cell lysates from each cell line were immunoprecipitated with the indicated antibody $(2 \mu \mathrm{g} / \mathrm{ml})$, followed by Western blot (lower panel). Cell lysates were also subjected to Western blot (upper panel). (B) Cell lysates of the indicated cell line were immunoprecipitated with the indicated antibody ( $2 \mu \mathrm{g} / \mathrm{ml})$, followed by Western blot (lower panel). Cell lysates were also subjected to Western blot (upper panel). (C) At $48 \mathrm{~h}$ after transfection with the indicated construct, cell lysates were immunoprecipitated with the indicated antibody $(2 \mu \mathrm{g} / \mathrm{ml})$, followed by Western blot (lower panel). Cell lysate were also subjected to Western blot (upper panel). (D) Malme3M cells were treated with celastrol $(1 \mu \mathrm{M})$ or taxol $(1 \mu \mathrm{M})$ for various time intervals. Cell lysates prepared at each time point were subjected to Western blot analysis. (E) Shows the proximal promoter sequences of tubulin $\beta 3$. (F) At $48 \mathrm{~h}$ after transfection with the indicated construct, ChIP assays were performed. Cell lysates prepared from untransfected Malme3M or SNU387 cells were also subjected to ChIP assays.

prevented by HDAC3 (Fig. 6C). YY1 possibly interacts with HDAC1 and/or HDAC2, and HDAC3 may prevent this interaction by negatively regulating expression of HDAC1 and/or HDAC2. The down-regulation of HDAC6 did not affect the expression of HDAC1, HDAC3 or YY1 (Fig. 6D). This indicated that HDAC1, HDAC3 and YY1 function upstream of HDAC6. The down- regulation of HDAC6 decreased the expression of MDR1 and tubulin $\beta 3$ (Fig. 6D). The down- regulation of HDAC6 enhanced sensitivity to taxol (Fig. 6E). The downregulation of HDAC6 enhanced sensitivity to celastrol (data not shown). Taken together, these results showed the regulatory role of HDAC3 in the expression of HDAC6. These results also showed that HDAC6 is a downstream target of HDAC3 and functions upstream of tubulin $\beta 3$ and MDR1.

\section{MDR1 is necessary for resistance to microtubule-targeting drugs}

Because HDAC3 regulated expression of MDR1 (Figs. 3A and $3 \mathrm{~B})$, we examined the role of MDR1 in resistance to microtubule-targeting drugs and the relationship between MDR1 and tubulin $\beta 3$. The down-regulation of MDR1 enhanced sensitivity to microtubule-targeting drugs (Fig. 7A). The down- regulation of MDR1 enhanced the microtubule-targeting drugs induced cleavages of PARP (Fig. 7B). Over- expression of HDAC3 in Malme $3 \mathrm{M}^{\mathrm{R}}$ or $\mathrm{SNU} 387^{\mathrm{R}}$ cells in the presence of MDR1 knock down did not further enhance sensitivity to microtubuletargeting drugs (Fig. 7C) or affect the knock down state of MDR1 (Fig. 7D). This suggested that MDR1 serves as a downstream target of HDAC3. HDAC3 decreased the expression of tubulin $\beta 3$ (Fig. 7D). Tubulin $\beta 3$ mediates resistance to microtubule-targeting drugs (Cittelly et al., 2012). The down-regulation of MDR1 did not affect expression of tubulin $\beta 3$ (Fig. 7D), suggesting that MDR1 and tubulin $\beta 3$ may serve as independent targets of HDAC3. Taken together, these results suggested that MDR1 serves as a downstream target of HDAC3 that affects response to microtubule-targeting drugs.

\section{DISCUSSION}

Microtubule-destabilizer-resistant cancer cell lines show an 

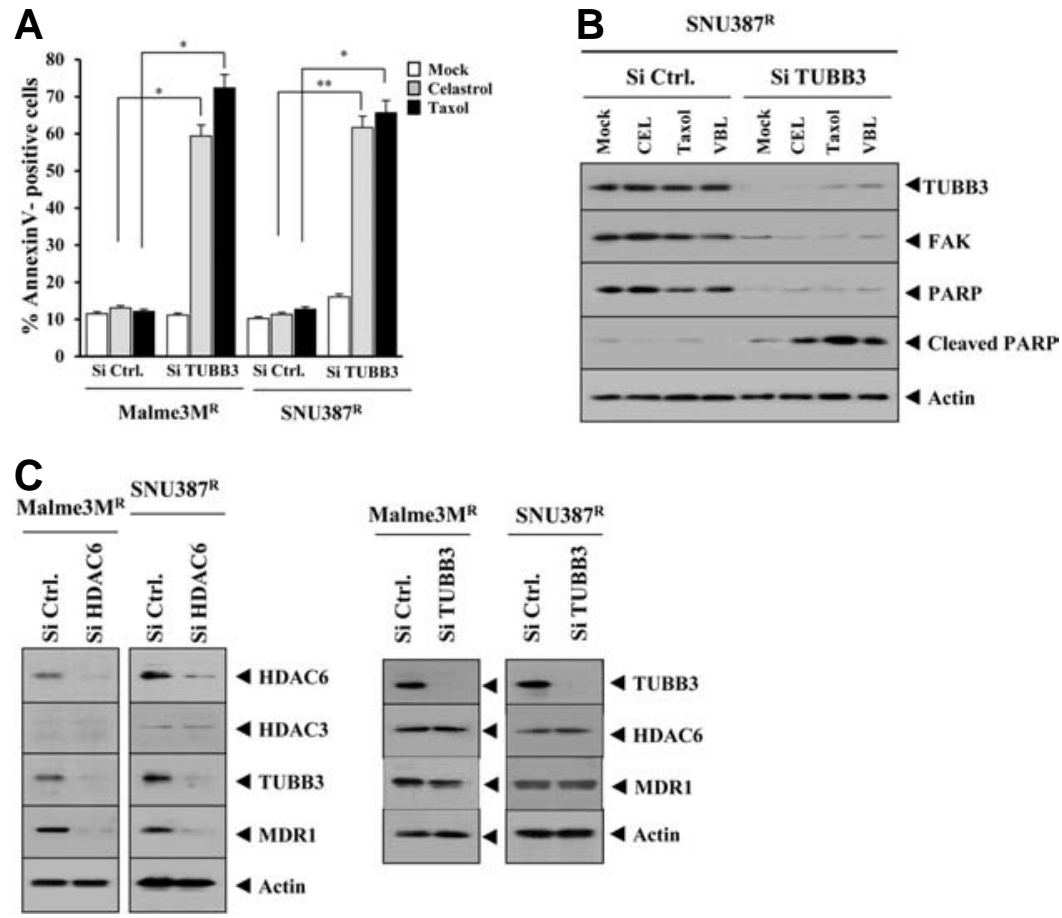

$\boldsymbol{A}$

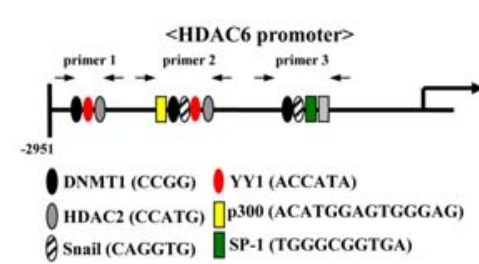

B

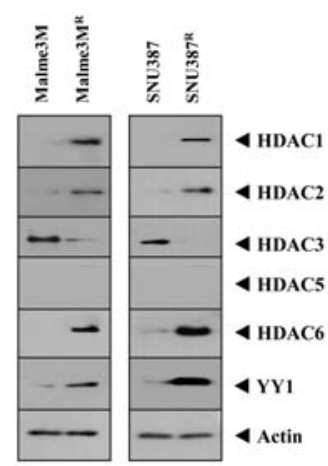

C

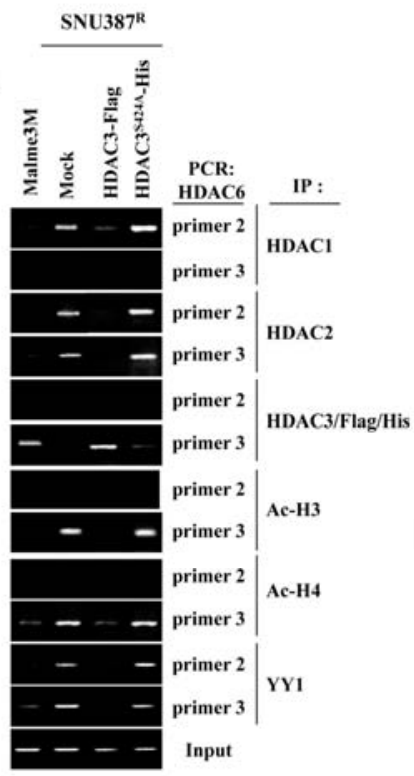

D

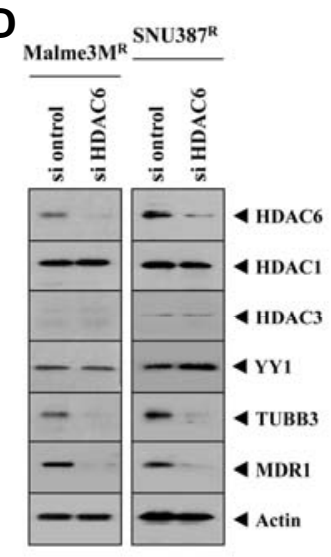

E

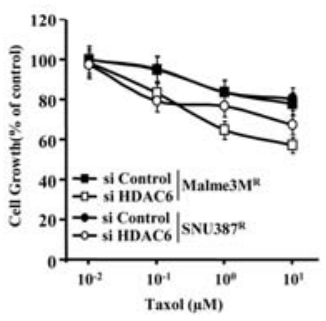

Fig. 5. Tubulin $\beta 3$ acts downstream of HDAC6, and the down-regulation of tubulin $\beta 3$ enhances sensitivity to microtubule-targeting drugs. (A) The indicated cell line was transfected with the indicated siRNA (10 nM each). The next day, cells were treated with various concentrations of the indicated drug for $24 \mathrm{~h}$, followed by annexin $\mathrm{V}$ FITC staining. ${ }^{*} p<0.05 ;{ }^{* *} p<0.005$. A comparison was made between SNU $387^{\mathrm{R}}$ or Malme $3 \mathrm{M}^{\mathrm{R}}$ cells transfected with control siRNA. (B) The same as $(A)$ except that Western blot was performed. (C) At $48 \mathrm{~h}$ after transfection with the indicated siRNA (10 nM each), Western blot was performed.
Fig. 6. HDAC3 directly regulates the expression of HDAC6 and the down-regulation of HDAC6 enhances sensitivity to taxol. (A) Shows the promoter sequences of the HDAC6. (B) Cell lysates isolated from the indicated cell line were subjected to Western blot analysis. (C) Cell lysates of the indicated cell line were immunoprecipitated with the indicated antibody $(2 \mu \mathrm{g} / \mathrm{ml})$, followed by ChIP assays. (D) SNU $387^{\mathrm{R}}$ or Malme $3 \mathrm{M}^{\mathrm{R}}$ cells were transfected with the indicated siRNA (10 $\mathrm{nM}$ each). At $48 \mathrm{~h}$ after transfection, cell lysates were prepared and subjected to Western blot analysis. (E) SNU $387^{R}$ or Malme $3 M^{R}$ cells were transfected with the indicated siRNA (10 nM each). At $24 \mathrm{~h}$ after transfection, cells were treated with various concentrations of taxol for $24 \mathrm{~h}$, followed by MTT assays. increased expression of survivin (Hei et al., 2010). Therefore $\mathrm{SNU}_{387^{\mathrm{R}}}$ and Malme3M ${ }^{\mathrm{R}}$ cells may show the increased expression of anti-apoptotic proteins such as survivin. The downregulation of anti-apoptotic prohibin enhances sensitivity to taxol (Patel et al., 2010). The enhanced sensitivity to microtu- bule-targeting drugs is related with caspase-3-depedent pathway as evidenced by cleavage of PARP (Figs. 3C and 3D). It will therefore be necessary to examine the effect of HDAC3 on caspase-independent cell death by examining the expression of anti-apoptotic proteins such as surviving and prohibin. 

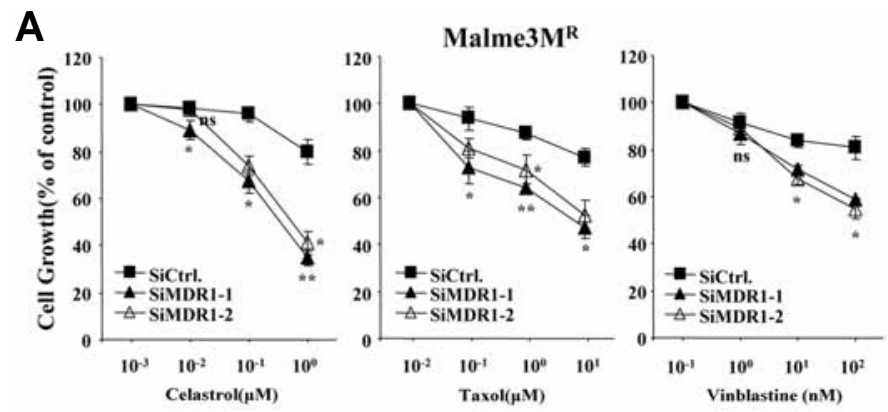

C

Malme3M $\mathbf{M}^{\mathrm{R}}$
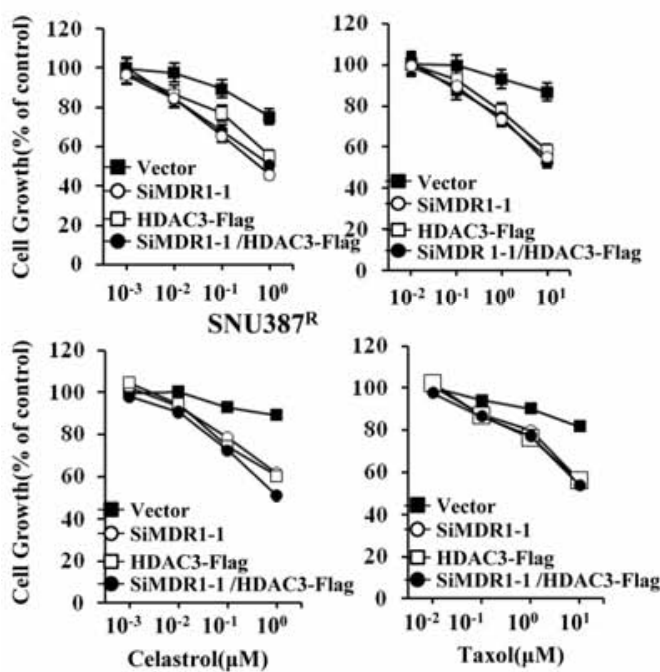

Fig. 7. MDR1 is necessary for resistance to microtubule-disrupting drugs. (A) Malme $3 \mathrm{M}^{\mathrm{R}}$ cells were transfected with indicated siRNA. The next day, cells were treated with or without various concentrations of celastrol, vinblastine or taxol for $24 \mathrm{~h} .{ }^{*} p<0.05 ;{ }^{* *} p<0.005$. $P$ value was determined in comparison with value obtained from Malme $3 \mathrm{M}^{R}$ transfected with scrambled siRNA. (B) Malme $3 \mathrm{M}^{R}$ cells were transfected with indicated siRNA (10 nM each). The next day, cells were treated with celastrol $(1 \mu \mathrm{M})$, taxol $(1 \mu \mathrm{M})$ or vinblastine $(100 \mathrm{nM})$ for $24 \mathrm{~h}$, followed by Western blot analysis. (C) The indicated cell line was transfected with the indicated construct alone or in combination. The next day, cells were treated with various concentrations of cealstrol or taxol for $24 \mathrm{~h}$, followed by MTT assays. (D) The indicated cell line was transfected with the indicated construct alone or in combination. Western blot analysis was performed at $48 \mathrm{~h}$ after transfection.

The MDR1 expression level is correlated with resistance to taxol and doxorubicin (Mechetner et al., 1998). It will be interesting to examine whether HDAC3 would also confer sensitivity to doxorubicin and examine the direct regulation of MDR1 by HDAC3. It will be necessary to examine the direct binding of the HDAC3 to the promoter sequences of MDR1. CDX2, a transcription factor, regulates MDR1 expression (Takakura et al., 2010) and the down-regulation of CDX2 enhances sensitivity to cisplatin, doxorubicin and 5-FU (Yan et al., 2013). It will be necessary to examine the effect of HDAC3 on the expression of CDX2.

The down-regulation of HDAC6 leads to the degradation of EGFR (Gao et al., 2010). We found an increased expression of EGFR in Mame $3 \mathrm{M}^{\mathrm{R}}$ cells. In addition, Malme $3 \mathrm{M}^{\mathrm{R}}$ cells show resistance to EGFR inhibitors (data not shown). The inhibition of EGFR by cetuximab enhances sensitivity to taxol (data not shown). It is probable that EGFR signaling may be responsible for the decreased expression of HDAC3 in SNU387 ${ }^{R}$ and Malme $3 M^{R}$ cells. It is also reasonable that HDAC3 may exert a negative control on the expression and/or activity of EGFR in
B

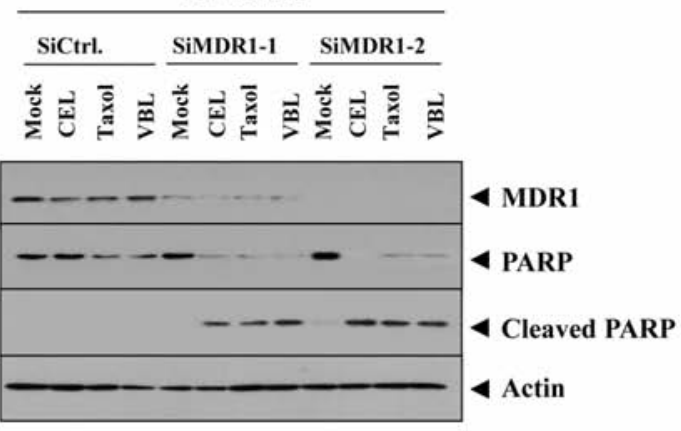

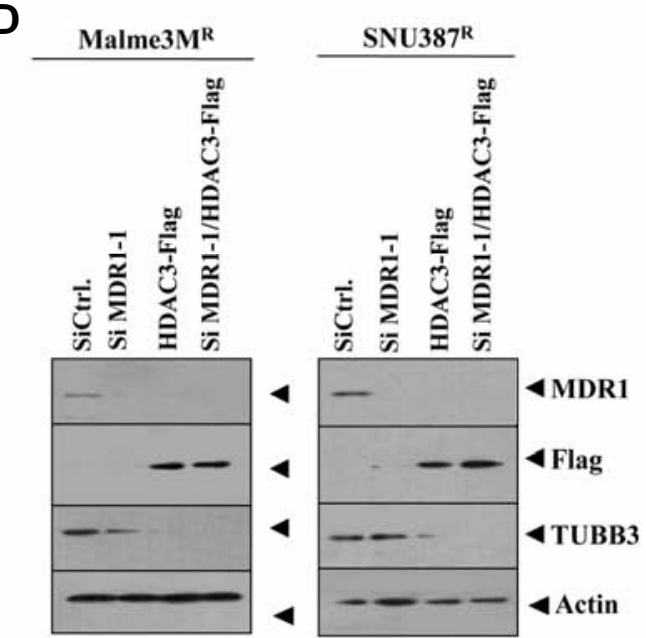


ty to taxol (Fig. 6E). Depletion of HDAC6 enhances cisplatininduced cytotoxicity by activating the ATR/Chk 1 pathway (Wang et al., 2012). These reports indicated the role of HDAC6 in anti-cancer drug-resistance. Because HDAC3 regulates the expression of HDAC6, it will be interesting to examine the effect of HDAC3 on the ATR/Chk1 pathway. Tubacin, a selective inhibitor of HDAC6, enhances DNA damage induced by etoposide or SAHA as indicated by increased accumulation of $\gamma \mathrm{H} 2 \mathrm{AX}$ and activation of the checkpoint kinase Chk2 (Namdar et al., 2010). It will also be interesting to examine the effect of HDAC3 in response to DNA damaging drugs.

HDAC6 is necessary for angiogenesis via its interaction with and deacetylation of the actin-remodeling protein cortactin, in endothelial cells (Kaluza et al., 2011). Because HDAC3 regulates the expression of HDAC6, it would be interesting to examine the effect of HDAC3 on the acetylation of cortactin. It will be necessary to examine the effect of HDAC3 on the expression of various angiogenic factor(s). Because HDAC3 confers sensitivity to microtubule-targeting drugs, it possibly exerts a negative effect on tumor-induced angiogenesis. VEGF signaling induces anti cancer drug-resistance by upregulating MDR1 expression (Akiyama et al., 2012). Because HDAC3 negatively regulates MDR1 expression, HDAC3 likely regulates the expression of VEGF.

MicroRNAs (miRNAs) are non-coding RNA molecules that mediate posttranscriptional gene regulation and are strongly implicated in cellular processes such as cell proliferation, carcinogenesis, cell survival and apoptosis. MiRNA-binding factor Lin-28 mediates taxol-resistance in breast cancer cells (Lv et al., 2012). miR-148a attenuates taxol-resistance by regulating MSK1 expression (Fujita et al., 2010). miR-337-3p modulates taxol-sensitivity by targeting STAT3 and RAP1A (Du et al., 2012). These reports suggest the role of miRNAs in taxolresistance. In this study, we identified miRNAs that were downregulated in Malme $3 \mathrm{M}^{\mathrm{R}}$ cells. These include miR-138, -189, $211,-324-3 p$ and -335 (data not shown). It is necessary to further examine the effect of these miRNAs on HDAC3 expression and response to microtubule-targeting drugs. In conclusion, we showed a novel role of HDAC3 in determining response to microtubule-targeting drugs. We showed that HDAC3-HDAC6tubulin $\beta 3$ axis determines response to microtubule-targeting drugs.

\section{ACKNOWLEDGMENTS}

This work was supported by National Research Foundation Grants (2014R1A2A2A01002448, 2015R1A1A3A04001339), a grant from the BK21 Plus Program, and by National R\&D Program for Cancer Control, Ministry for Health and Welfare, Republic of Korea Grant 1320160.

\section{REFERENCES}

Akiyama, K., Ohga, N., Hida, Y., Kawamoto, T., Sadamoto, Y., Ishikawa, S., Maishi, N., Akino, T., Kondoh, M., Matsuda, A., et al. (2012). Tumor endothelial cells acquire drug resistance by MDR1 up-regulation via VEGF signaling in tumor microenvironment. Am. J. Pathol. 180, 1283-1293.

Bonet, C., Giuliano, S., Ohanna, M., Bille, K., Allegra, M., Lacour, J.P., Bahadoran, P., Rocchi, S., Ballotti, R., and Bertolotto, C (2012). Aurora $B$ is regulated by the mitogen-activated protein kinase/extracellular signal-regulated kinase (MAPK/ERK) signaling pathway and is a valuable potential target in melanoma cells. J. Biol. Chem. 287, 29887-29898.

Chae, S., Kim, Y.B., Lee, J.S., and Cho, H. (2012). Resistance to paclitaxel in hepatoma cells is related to static JNK activation and prohibition into entry of mitosis. Am. J. Physiol. Gastrointest. Liver Physiol. 302, 1016-1024.
Chen, L.F., Fischle, W., Verdin, E., and Greene, W.C. (2001). Duration of nuclear NF-kappaB action regulated by reversible acetylation. Science 293, 1653-1657.

Cittelly, D.M., Dimitrova, I., Howe, E.N., Cochrane, D.R., Jean, A., Spoelstra, N.S., Post, M.D., Lu, X., Broaddus, R.R., Spillman, M.A., et al. (2012). Restoration of miR-200c to ovarian cancer reduces tumor burden and increases sensitivity to paclitaxel. Mol. Cancer Ther. 11, 2556-2565.

Du, L., Subauste, M.C., DeSevo, C., Zhao, Z., Baker, M., Borkowski, R., Schageman, J.J., Greer, R., Yang, C.R., Suraokar, M., et al. (2012). miR-337-3p and its targets STAT3 and RAP1A modulate taxane sensitivity in non-small cell lung cancers. PLoS One 7, e39167.

Fadri-Moskwik, M., Weiderhold, K.N., Deeraksa, A., Chuang, C., Pan, J., Lin, S.H., and Yu-Lee, L.Y. (2012). Aurora B is regulated by acetylation/deacetylation during mitosis in prostate cancer cells. FASEB J. 26, 4057-4067.

Fujita, Y., Kojima, K., Ohhashi, R., Hamada, N., Nozawa, Y., Kitamoto, A., Sato, A., Kondo, S., Kojima, T., Deguchi, T., et al. (2010). MiR-148a attenuates paclitaxel resistance of hormonerefractory, drug-resistant prostate cancer PC3 cells by regulating MSK1 expression. J. Biol. Chem. 285, 19076-19084.

Gao, Y.S., Hubbert, C.C., and Yao, T.P. (2010). The microtubuleassociated histone deacetylase 6 (HDAC6) regulates epidermal growth factor receptor (EGFR) endocytic trafficking and degradation. J. Biol. Chem. 285, 11219-11226.

Hei, C., Cheung, A., Wu, S.Y., Lee, T.R., Chang, C.Y., Wu, J.S Hsieh, H.P., and Chang, J.Y. (2010). Cancer cells acquire mitotic drug resistance properties through beta I-tubulin mutations and alterations in the expression of beta-tubulin isotypes. PLoS One 5, e12564.

Hubbert, C., Guardiola, A., Shao, R., Kawaguchi, Y., Ito, A., Nixon, A., Yoshida, M., Wang, X.F., and Yao, T.P. (2002). HDAC6 is a microtubule-associated deacetylase. Nature 417, 455-458.

Ishii, S., Kurasawa, Y., Wong, J., and Yu-Lee, L.Y. (2008). Histone deacetylase 3 localizes to the mitotic spindle and is required for kinetochore-microtubule attachment. Proc. Natl. Acad. Sci. USA 105, 4179-4184.

Kaluza, D., Kroll, J., Gesierich, S., Yao, T.P., Boon, R.A., Hergenreider, E., Tjwa, M., Rössig, L., Seto, E., Augustin, H.G., et al. (2011). Class llb HDAC6 regulates endothelial cell migration and angiogenesis by deacetylation of cortactin. EMBO J. 30, 4142-4156.

Kamath, K., Wilson, L., Cabral, F., and Jordan, M.A. (2005). Betallltubulin induces paclitaxel resistance in association with reduced effects on microtubule dynamic instability. J. Biol. Chem. 280, 12902-12907.

Kavallaris, M., Kuo, D.Y., Burkhart, C.A., Regl, D.L., Norris, M.D. Haber, M., and Horwitz, S.B. (1997). Taxol-resistant epithelial ovarian tumors are associated with altered expression of specific beta-tubulin isotypes. J. Clin. Invest. 100, 1282-1293.

Kim, H.C., Choi, K.C., Choi, H.K., Kang, H.B., Kim, M.J., Lee, Y.H., Lee, O.H., Lee, J., Kim, Y.J., Jun, W., et al. (2010a). HDAC3 selectively represses CREB3-mediated transcription and migration of metastatic breast cancer cells. Cell. Mol. Life Sci. 67, 34993510.

Kim, Y., Park, H., Park, D., Lee, Y.S., Choe, J., Hahn, J.H., Lee, H. Kim, Y.M., and Jeoung, D. (2010b). Cancer/testis antigen CAGE exerts negative regulation on p53 expression through HDAC2 and confers resistance to anti-cancer drugs. J. Biol. Chem. 285, 25957-25968.

Levallet, G., Bergot, E., Antoine, M., Creveuil, C., Santos, A.O Beau-Faller, M., de Fraipont, F., Brambilla, E., Levallet, J., Morin, F., et al. (2012). High TUBB3 expression, an independent prognostic marker in patients with early non-small cell lung cancer treated by preoperative chemotherapy, is regulated by K-Ras signaling pathway. Mol. Cancer Ther. 11, 1203-1213.

Li, J., Wang, J., Wang, J., Nawaz, Z., Liu, J.M., Qin, J., and Wong, J. (2000). Both corepressor proteins SMRT and N-CoR exist in large protein complexes containing HDAC3. EMBO J. 19, 43424350.

Lv, K., Liu, L., Wang, L., Yu, J., Liu, X., Cheng, Y., Dong, M., Teng, R., Wu, L., Fu, P., et al. (2012). Lin28 mediates paclitaxel resistance by modulating p21, Rb and Let-7a miRNA in breast cancer cells. PLoS One 7, e40008.

Mahlknecht, U., Emiliani, S., Najfeld, V., Young, S, and Verdin, E. 
(1999). Genomic organization and chromosomal localization of the human histone deacetylase 3 gene. Genomics 56. 197-202.

Mahlknecht, U., Will, J., Varin, A., Hoelzer, D., and Herbein, G. (2004). Histone deacetylase 3 , a class I histone deacetylase, suppresses MAPK11-mediated activating transcription factor-2 activation and represses TNF gene expression. J. Immunol. 173, 3979-3990.

Mechetner, E., Kyshtoobayeva, A., Zonis, S., Kim, H., Stroup, R. Garcia, R., Parker, R.J., and Fruehauf, J.P. (1998) Levels of multidrug resistance (MDR1) P-glycoprotein expression by human breast cancer correlate with in vitro resistance to taxol and doxorubicin. Clin. Cancer Res. 4, 389-398.

Namdar, M., Perez, G., Ngo, L., Paul, A., and Marks, P.A. (2010). Selective inhibition of histone deacetylase 6 (HDAC6) induces DNA damage and sensitizes transformed cells to anticancer agents. Proc. Natl. Acad. Sci. USA 107, 20003-20008.

Ott, P.A., Chang, J., Madden, K., Kannan, R., Muren, C., Escano, C., Cheng, X., Shao, Y., Mendoza, S., Gandhi, A., et al. (2013) Oblimersen in combination with temozolomide and albuminbound paclitaxel in patients with advanced melanoma: a phase I trial. Cancer Chemother. Pharmacol. 71, 183-191.

Owonikoko, T.K., Ramalingam, S.S., Kanterewicz, B., Balius, T., Belani, C.P., and Hershberger, P.A. (2010). Vorinostat increases carboplatin and paclitaxel activity in non-small cell lung cancer cells. Int. J. Cancer 126, 743-755.

Patel, N., Chatterjee, S.K., Vrbanac, V., Chung, I., Mu, C.J., Olsen, R.R., Waghorne, C., and Zetter, B.R. (2010). Rescue of paclitaxel sensitivity by repression of Prohibitin1 in drug-resistant cancer cells Proc. Natl. Acad. Sci. USA 107, 2503-2508.

Seve, P., Reiman, T., and Dumontet, C. (2010). The role of betall tubulin in predicting chemoresistance in non-small cell lung cancer. Lung Cancer 67, 136-143.

Takakura, Y., Hinoi, T., Oue, N., Sasada, T., Kawaguchi, Y., Okajima, M., Akyol, A., Fearon, E.R., Yasui, W., and Ohdan, H. (2010). CDX2 regulates Multidrug Resistance 1 gene expression in malignant intestinal epithelium. Cancer Res. 70, 67676778.

Verdier-Pinard, P., Wang, F., Martello, L., Burd, B., Orr, G.A., and Horwitz, S.B. (2003). Analysis of tubulin isotypes and mutations from taxol-resistant cells by combined isoelectrofocusing and mass spectrometry. Biochemistry 42, 5349-5357.

Wang, L., Xiang, S., Williams, K.A., Dong, H., Bai, W., Nicosia, S.V., Khochbin, S., Bepler, G., and Zhang, X. (2012). Depletion of HDAC6 enhances cisplatin-induced DNA damage and apoptosis in non-small cell lung cancer cells. PLoS One 7, e44265.

Xie, H., Lee, M.H., Zhu, F., Reddy, K., Peng, C., Li, Y., Lim do, Y., Kim, D.J., Li, X., Kang, S., et al. (2013). Identification of an Aurora kinase inhibitor specific for the Aurora B isoform. Cancer Res. 73, 716-724

Xu, R., Sato, N., Yanai, K., Akiyoshi, T., Nagai, S., Wada, J., Koga, K., Mibu, R., Nakamura, M., and Katano, M. (2009). Enhancement of paclitaxel-induced apoptosis by inhibition of mitogenactivated protein kinase pathway in colon cancer cells. Anticancer Res. 29, 261-270.

Xu, R., Nakano, K., Iwasaki, H., Kumagai, M., Wakabayashi, R., Yamasaki, A., Suzuki, H., Mibu, R., Onishi, H., and Katano, M. (2011). Dual blockade of phosphatidylinositol 3'-kinase and mitogen-activated protein kinase pathways overcomes paclitaxelresistance in colorectal cancer. Cancer Lett. 306, 151-160.

Yan, L.H., Wang, X.T., Yang, J., Lian, C., Kong, F.B., Wei, W.Y., Luo, W., Xiao, Q., and Xie, Y.B. (2013). Reversal of multidrug resistance in gastric cancer cells by CDX2 downregulation. World J. Gastroenterol. 19, 4155-4165.

Yao, Y.L., Yang, W.M., and Seto, E. (2001). Regulation of transcription factor YY1 by acetylation and deacetylation. Mol. Cell Biol. 21, 5979-5991.

Yin, S., Bhattacharya, R., and Cabral, F. (2010). Human mutations that confer paclitaxel resistance. Mol. Cancer Ther. 9, 327.

Zhang, J., Kalkum, M., Chait, B.T., and Roeder, R.G. (2002). The $\mathrm{N}$-CoR-HDAC3 nuclear receptor corepressor complex inhibits the JNK pathway through the integral subunit GPS2. Mol. Cell 9, 611-623.

Zhang, Y., Li, N., Caron, C., Matthias, G., Hess, D., Khochbin, S. and Matthias, P. (2003). HDAC-6 interacts with and deacetylates tubulin and microtubules in vivo. EMBO $\mathrm{J} 22$ 1168-1179.

Zhang, X., Ozawa, Y., Lee, H., Wen, Y.D., Tan,T.H., Wadzinski, B.E., and Seto, E. (2005). Histone deacetylase 3 (HDAC3) activity is regulated by interaction with protein serine/threonine phosphatase 4. Genes Dev. 19, 827-839. 